\title{
Stream-Flow Response to Climate Change and Human Activities in an Upstream Catchment of Huai River
}

\author{
Peng Shi ${ }^{1,2^{*}}$, Miao $\mathrm{Wu}^{2}$, Xinxin $\mathrm{Ma}^{2}$, Simin $\mathrm{Qu}^{2}$, Xueyuan $\mathrm{Qiao}^{2}$ \\ ${ }^{1}$ State Key Laboratory of Hydrology-Water Resources and Hydraulic Engineering, Hohai University, \\ Nanjing, China \\ ${ }^{2}$ College of Water Resources and Hydrology, Hohai University, Nanjing, China \\ Email: ship@hhu.edu.cn
}

Received November 2014

\begin{abstract}
Climate change and human activities have great implications for hydrological process and water projects planning. In order to evaluate the impacts on stream-flow, statistical methods and SWAT model are applied to this research. The results indicate that the abrupt change year (1965) of annual stream-flow is chosen as the split point of natural and human influenced (particularly reservoirs) periods. The calibrated SWAT model is proved to be applicable in this catchment and is used to simulate the monthly runoff which can be regarded as the natural runoff induced by climate change. A major finding of this study is that the reservoir regulations have apparently altered the monthly and seasonal stream-flow regimes. By quantifying the impacts of climate variation and human activities, the decreasing trend of annual stream-flow is found, and human activities are proved to be the dominant role in the catchment. This research improves our knowledge of hydrological responses to natural and artificial factors, and provides a better understanding for the future reservoir regulations.
\end{abstract}

\section{Keywords}

Trend and Saltation Analysis, SWAT Model, Climate Change, Human Activities, Stream-Flow

\section{Introduction}

The scientific knowledge of hydrological processes and their responses to climate change and human activities is of great importance in both theoretical and practical meaning, attracting numerous researches around the world (Wu \& Johnston, 2007). Climate change caused by increasing atmospheric concentration of carbon dioxide and other micro gases has altered the magnitude and timing of runoff to some extend. In addition to climate oriented variations, human activities such as land use changes (Guo et al., 2008; Shi et al., 2013b), constructions of water conservancy projects, interbasin water diversions and industrial and agricultural needs have taken pro-

\footnotetext{
"Corresponding author.
}

How to cite this paper: Shi, P., Wu, M., Ma, X. X., Qu, S. M., \& Qiao, X. Y. (2014). Stream-Flow Response to Climate Change and Human Activities in an Upstream Catchment of Huai River. Journal of Geoscience and Environment Protection, 2, 68-78. http://dx.doi.org/10.4236/gep.2014.25010 
nounced influences in hydrological regimes (Rinaldi, 2003; Ye et al., 2003; Magilligan \& Mislowb, 2005; Isik et al., 2008). Therefore, the effects of the two factors have important implications on the existing water resources system as well as on the future planning and management of water projects (Guo et al., 2002). It is considerably significant for understanding the effects of climate change and human activities on stream-flow, especially quantifying the degree of the influences.

In recent years, a large number of attempts have been made in these fields to estimate the impacts caused by natural or human induced. The Assessment Reports of the Intergovernmental Panel on Climate Change (IPCC, 1995, 2007) aroused the awareness of the threats caused by climate change and indicated that it is crucial to bring climate change onto the policy agendas (Editorial, 2008; Hofmann et al., 2011). Kottegoda et al. (2011) described the development of new techniques of simulating trends and periodicities from Gibbs sampling derived from observed rainfall series, and provided possible climate scenarios which have wide uses in the planning, designing and operation of water resources system. Lajoie et al. (2007) compared the monthly flow characteristics based on different watershed areas and studied the impacts of natural rivers and reservoir-regulated rivers. The results showed that the dams alter the hydrologic regimes but the magnitude is variable depending on the watershed size and the season. Isik et al. (2008) examined the effects of human activities on the Lower Sakarya River, and pointed clearly that how anthropogenic activities can alter the hydrology and morphology in the river. Zhang et al. (2010) proposed a quantitative framework to estimate the impact of dams and floodgates on the river flow regimes and water quality in the middle and upper reaches of the Huai River Basin. This research will provide a foundation to achieve the anti-pollution and the integrated water quantity and quality assessment of dams and floodgates. Ye et al. (2003) systematically investigated the long-term monthly and yearly runoff data for the major sub-basins in the Lena River watershed, and documented the significant hydrology changes induced by human activities (especially the operation of reservoirs) and by natural variations. This study clearly illustrated the importance of human activities in regional and global environment changes.

Meanwhile, the model-based researches are widely interesting along different authors. A set of monthly water balance models such as a semi-distributed model (Guo et al., 2002) were developed for studying the impacts of climate change on the hydrological cycle and for the planning and management of water resources system (Mimikou et al., 1991; Panagoulia \& Dimou, 1997; Xu \& Singh, 1998). Guo et al. (2008) and Shi et al. (2013b) based on the Soil and Water Assessment Tool (SWAT) analyzed the hydrological responses to land-use and climate change, the results revealed that the climate effect was dominant in the annual stream-flow, and in Shi's study he also found out that the climate variability played a counteractive role compared with the land use change. Dong (2010) and Shi (2011) used the SWAT model to simulate the runoff in different time periods; they quantified the human activities and climate change by comparing the pre- and post-saltation year. Their researches indicated that human activities played a significant role in the runoff variation. The assessments of differentiated impacts on climate change and human activities provided guidance for the effectively developing and managing water resources projects for future sustainability and productivities.

The focus area of this study is the Shaying River which is the first tributary in the upstream of Huai River (Wang, 2000; Shi et al., 2013a). The length of the main river is $620 \mathrm{~km}$ and the total drainage area is approximately $4000 \mathrm{~km}^{2}$. The catchment contains 31.8 million mu cultivated land with 24 million populations, and abundant coal resources, so it is an important energy base and has a bright developing prospects for agricultural and industrial fields. In the last 60 years, 4 large reservoirs, including Baisha (BS), Zhaopingtai (ZPT), Baiguishan (BGS) and Gushitan (GST), and 14 medium reservoirs as well as more than 100 small reservoirs were constructed in the catchment, the total capacity was 3.05 billion cubic meters, and the floods was effectively controlled by these water projects. Nowadays, the increasing climate change and anthropogenic activities bring much pressure on the management of water projects, therefore, it is crucial to understand the effects of the two factors on hydrological processes. Besides, the quantitative study in the area is relatively few; this paper is the first endeavor in the Shaying River catchment attempting to quantify the effects of climate change and anthropogenic activities on stream-flow.

\section{Materials and Methodology}

\subsection{Study Area}

Shaying River, as the first tributary in the upper reach of Huai River, originated in the western mountainous area of Henan province and flows through Pingdingshan, Luohe, Xuchang, Zhoukou and Fuyang City etc. The 
Shaying River catchment is located between $111.95^{\circ}-114.03^{\circ} \mathrm{E}$ and $33.07^{\circ}-34.42^{\circ} \mathrm{N}$ and covers an area of 12,150 $\mathrm{km}^{2}$ above the Luohe (LH) station with three branches named Sha River, Li River and Beiru River (Figure 1). The terrain tilts from northwest to southeast and the mountainous area accounts for nearly $75 \%$ in the catchment. In 1960s, three large reservoirs (ZPT, BGS and GST) with the control areas of 1430, 1310 and 286 $\mathrm{km}^{2}$ respectively, have been built in the upstream of Shaying River, effectively regulated the medium and small floods. The catchment situated in the south-north climate transition zone and has a continental monsoon climate. The annual precipitation is 650 - $1400 \mathrm{~mm}$, and the distribution of rainfall is extremely uneven, nearly $42 \%$ of total rainfall concentrates on rainy season from June to September, and most between July and August. The annual average temperature differs widely in the region, it is between $10.7^{\circ} \mathrm{C}-12.9^{\circ} \mathrm{C}$ in the western mountains and within $14.5^{\circ} \mathrm{C}-14.9^{\circ} \mathrm{C}$ in the eastern plains.

\subsection{Model, Data and Model Calibration}

In this study, the Soil and Water Assessment Tool (SWAT) was used to evaluate the influences of human activities and climate change on stream-flow (Zhang et al., 2007; Gebremicael et al., 2013; Shi et al., 2013b), and then quantified the effects of the two factors. SWAT model is a river basin, or watershed scale model, which is developed to predict the impact of land management practices on water, sediment, and agricultural chemical yields in large, complex watersheds with varying soils, land use, and management conditions over long periods of time (Arnold et al., 1998; Neitsch et al., 2005a, b). In the model, a study basin is divided into multiple sub-basins which are connected by surface flow, and then the sub-basins are further subdivided into one or more hydrologic response units (HRUs) with a homogenous land use, soil types, slope and management practice. In each HRU, hydrological components in water budget for surface, soil and groundwater are calculated independently, and then the calculation results are collected to the basin outlet (Guo et al., 2008).

Data required by SWAT in this study include the topography, soil properties, land-use types, hydro-meteorological data and observed discharge; all of them were collected and detailed as follows:

(1) Digital elevation model (DEM). The resolution of the catchment DEM is $30 \mathrm{~m} \times 30 \mathrm{~m}$, and the projected coordinate system was converted to Beijing_1954_3_Degree_GK_Zone_38.

(2) Land use. The land-use map of 1980 at a scale of 1:210,000 was used, and it has also been converted to the same projected coordinate system as the DEM; meanwhile a user lookup table was created to connect the SWAT code with the land-use map. The land-use in this study area was reclassified into dry land (69.21\%), forestland (19.85\%), grassland (7.33\%), water (1.48\%) and residential area (2.64\%).

(3) Soils. The soil map with the same projected coordinate system as the DEM is at a scale of 1:100,000 and the soil properties were mainly collected from China Soil Scientific Database (http://www.soil.csdb.cn/). The particle sizes were transformed to be used in SWAT model by the cubic spine interpolation method and the other parameters were calculated by the Soil-Plant-Air-Water (SPAW) model (Saxton and Willey, 2005).

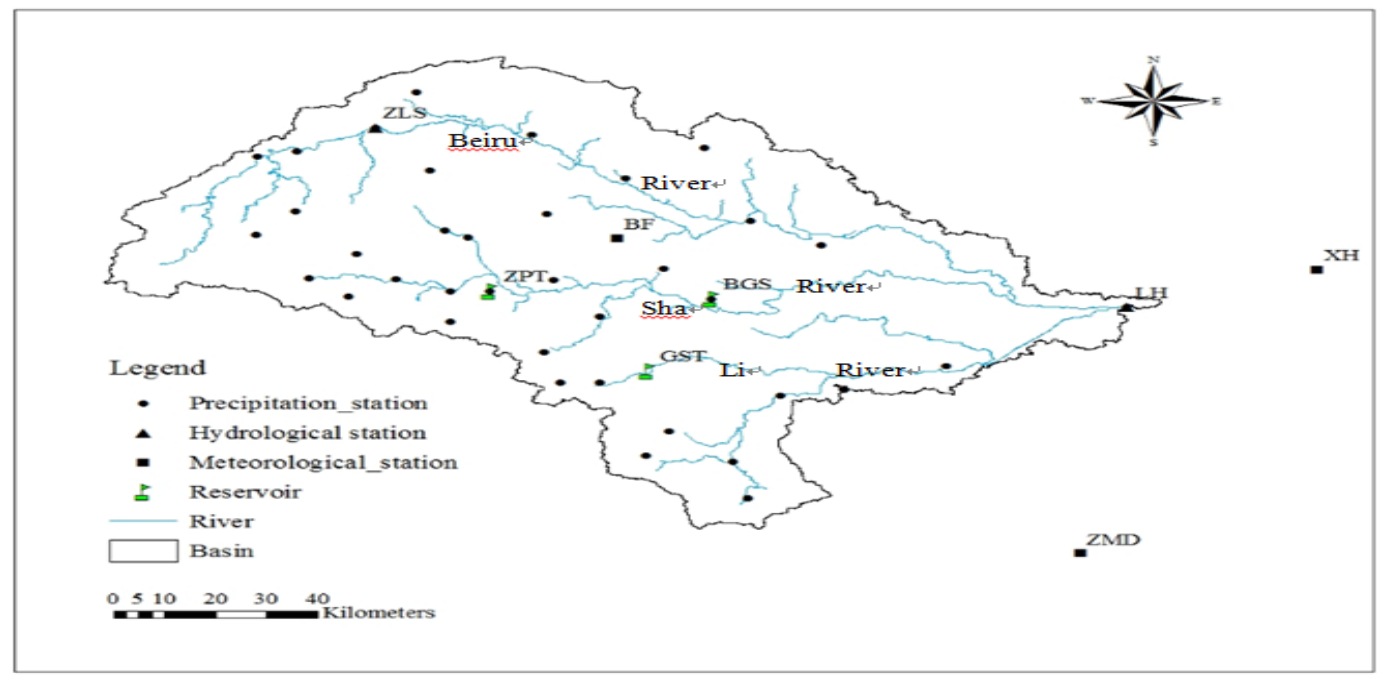

Figure 1. Study area and locations of the hydro-meteorological stations. 
(4) Hydro-meteorological data. Daily precipitation data from 38 rainfall stations, and daily maximum and minimum temperatures, relative humidity, solar radiation, wind speed data from 3 meteorological stations were collected (Figure 1). Monthly hydro-meteorological data were also required in the weather generator of SWAT model to simulate the missing daily data, which were computed by the Swat-weather software. Thus, the daily data series were extended to the period of 1951-2010, with the missing records were replaced by -99 .

(5) Observed discharge data. The daily observed stream-flow data of two hydrological stations, including Ziluoshan (ZLS) station (from 1952-2010) and Luohe (LH) station (from 1951-2010), were obtained and used to compare against the simulated data by the SWAT model.

There are a large number of parameters in the SWAT model; therefore, it is significant to identify the sensitive parameters to improve the calibration efficiency. The Latin Hypercube One-factor-At-a-Time (LH-OAT) method is used in the SWAT model to conduct the sensitive analysis (Morris, 1991; Saltelli, 2000). Then the SWAT-CUP, which linked calibration, validation, sensitivity and uncertainty analysis to SWAT model, was applied to implement the model calibration, we chose the Generalized Likelihood Uncertainty Estimation (GLUE) method (Beven and Binley, 1992; Romanowicz et al., 1994) in this process. After calibration, some performance indictors should be chosen to evaluate the application of SWAT model (Santhi et al., 2001; Moriasi et al., 2007). In this study, relative error $(R E)$, coefficient of determination $\left(R^{2}\right)$ and Nash-Sutcliff efficiency $\left(E_{n s}\right)$ were used as the criteria.

$R E$ indicates the average tendency of the simulated data to be smaller or larger than the observed data. When the absolute value of $R E$ is lower than $20 \%$, the accuracy of model simulation is better. $R^{2}$ is an indicator of the strength of the relationship between the measured and simulated records and describes the proportion of the total variance in the observed data that can be explained by the model. It ranges from 0 to 1 , the higher the value the better the performance. $E_{n s}$ represents the efficiency of the simulation and reveals how well the plot of the observed data versus the simulated data fits the 1:1 line, it varies between and 1 , the closer the value to 1 the better the model simulation (Legates and McCabe, 1999; Zhang et al., 2007).

\subsection{Trend and Saltation Analysis Methods}

A non-parametric test, namely the Mann-Kendall (MK) method, was used to detect the monotonic trends and saltation points of precipitation, temperature, and stream-flow. Meanwhile, the Orderly Clustering Method was also applied to confirm the change points of the three factors.

\section{Results and Discussions}

\subsection{Trend Analysis in Precipitation, Stream-Flow and Temperature}

Figure 2 shows the trends of the annual precipitation, stream-flow and temperature in Shaying River catchment (1954-2010). Since the $R^{2}$ value for precipitation is considerably small, and the trend line is quite flat, the variation trend of annual precipitation is slight. As to annual stream-flow and temperature, we can see that the stream-flow shows a decreasing trend with the change rate of $-7.12 \mathrm{~mm} / 10 \mathrm{a}$, while the temperature indicates an increasing trend with the rate of $0.18^{\circ} \mathrm{C} / 10 \mathrm{a}$. These different changes of the three factors indicate that the relationship between the annual precipitation and stream-flow is relatively small, and the decrease in stream-flow may due to the increasing annual temperature which will result in an increase of evaporation.

In order to better understand the degree of the variations, the MK test is carried out to detect the significance of the trends in annual and seasonal scales. The results are summarized in Table 1. The annual and seasonal trends of precipitation are all not significant, and except for autumn, other seasons represent upward trends. The slope value for summer precipitation is 0.65 , and the one for autumn is -0.186 , the opposite change degree may explain the reason for the moderate increasing annual precipitation. The stream-flow shows decreasing trends in annual and seasonal scales, the confidence level of the trends exceed 95\%, 90\%, 90\% in spring, winter and annual, respectively. The slope values for the three time series are $-0.288,-0.189$ and -0.609 , respectively, indicating that the integrated decreasing trend for stream-flow in different time series leading to a relatively larger decreasing trend in annual series. For temperature, the increasing trends are statistically significant at 99\% confidence level in spring, autumn, winter and annual, with the slope values of $0.03,0.017,0.031$ and 0.02 , respectively. While the downward trend in summer is not significant. These analyses again revealed that the increasing temperature brings about the decreasing stream-flow both in annual and seasonal scales, but whether it is the 


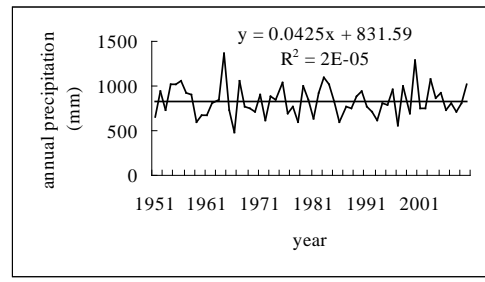

(a)

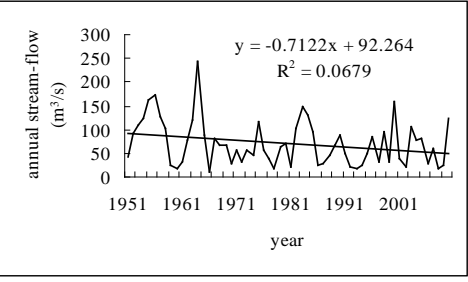

(b)

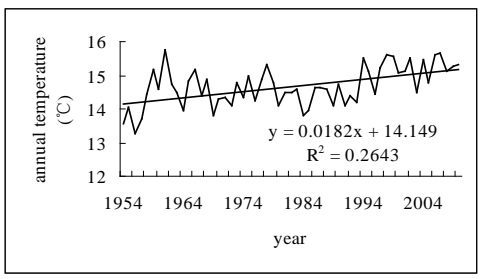

(c)

Figure 2. Trends for (a) annual precipitation (1951-2010); (b) stream-flow (1951-2010) and (c) temperature (1954-2010).

Table 1. Values of $\mathrm{Z}$ and the Slope $\beta$ for annual and seasonal Precipitation, Stream-flow and temperature.

\begin{tabular}{cccccccccc}
\hline \multirow{2}{*}{$\begin{array}{c}\text { Time } \\
\text { series }\end{array}$} & \multicolumn{3}{c}{ Precipitation $(\mathrm{mm})$} & \multicolumn{3}{c}{ Stream-flow $\left(\mathrm{m}^{3} / \mathrm{s}\right)$} & \multicolumn{3}{c}{ Temperature $\left({ }^{\circ} \mathrm{C}\right)$} \\
\cline { 2 - 9 } & $\mathrm{Z}$ & $\beta$ & Trend & $\mathrm{Z}$ & $\beta$ & Trend & $\mathrm{Z}$ & $\beta$ & Trend \\
\hline Spring & 0.134 & 0.082 & - & $-2.073^{* *}$ & -0.288 & $\downarrow$ & $3.593^{* * *}$ & 0.03 & $\uparrow$ \\
Summer & 0.491 & 0.65 & - & -1.346 & -1.101 & - & -0.447 & -0.003 & - \\
Autumn & -0.287 & -0.186 & - & -1.55 & -0.413 & - & $3.215^{* * *}$ & 0.017 & $\uparrow$ \\
Winter & 0.032 & 0.015 & - & $-1.958^{*}$ & -0.189 & $\downarrow$ & $3.215^{* * *}$ & 0.031 & $\uparrow$ \\
Annual & 0.083 & 0.06 & - & $-1.881^{*}$ & -0.609 & $\downarrow$ & $3.793^{* * *}$ & 0.02 & $\uparrow$ \\
\hline
\end{tabular}

Note: $\uparrow$ means upward trend, $\downarrow$ means downward trend, - means no trend ${ }^{*}$ Trends statistically significant at the $90 \%$ confidence level, ${ }^{* *}$ Trends statistically significant at the $95 \%$ confidence level, ${ }^{* * *}$ Trends statistically significant at the $99 \%$ confidence level

major factor and to what extend the influences reach, some further studies are required.

\subsection{Saltation Analysis in Precipitation, Stream-Flow and Temperature}

By means of the orderly clustering method and MK abrupt change test, the change points are investigated (Figures 3-5). According to the descriptions in the above theory, we can conclude that the saltation years for the annual precipitation, stream-flow and temperature are 1958, 1965 and 1993, respectively. The analysis is believable for the results of the two methods are the same. This different change points for the three variables may come from the effects of human activities such as land-use changes and constructions of water conservancy projects. Connected with the former analysis, we could obtain the following conclusions: the abrupt point for annual stream-flow occurs in the year 1965 (Figure 4) which is approximately accordance with the operation year of the three reservoirs, and in the year, the annual stream-flow decreased suddenly; meanwhile, the year lags behind the saltation year 1958 of annual precipitation (Figure 3), and stays ahead of the abrupt year 1993 of annual temperature (Figure 5); besides, the variation of stream-flow is inconsistent with the change of precipitation and temperature, and trend for precipitation is not obvious whereas the stream-flow indicates a significant decreasing trend. These results reveal that the effect of climate change is relatively smaller than that of human activities.

\subsection{Parameters Calibration and Applicability Analysis of SWAT Model}

The LH-OAT method in SWAT model is used to analyze the sensitive of different flow parameters, then the top five most sensitive parameters and another three default parameters which are relatively sensitive in the SWAT-CUP are used to calibrate the model. According to the former analyses of the trend and saltation, we choose the period 1953-1964 as the initial situation. In the first two years (1951-1952), which is the period when the model is equilibrating itself, the simulation result is not accurate enough; then the years $1953-1960$ are used as the calibration period, and the years 1961-1964 as the validation period. The best values of the 8 parameters calibrated by SWAT-CUP are listed in Table 2.

Applying these optimal values to SWAT model, we can get the simulated results for calibration and validation periods (Figure 6). The results can be concluded that for the calibration period of 1953-1960, RE = 3.01\%, 


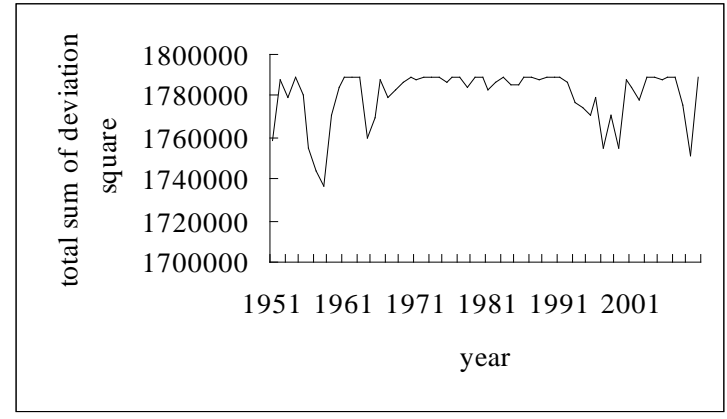

(a)

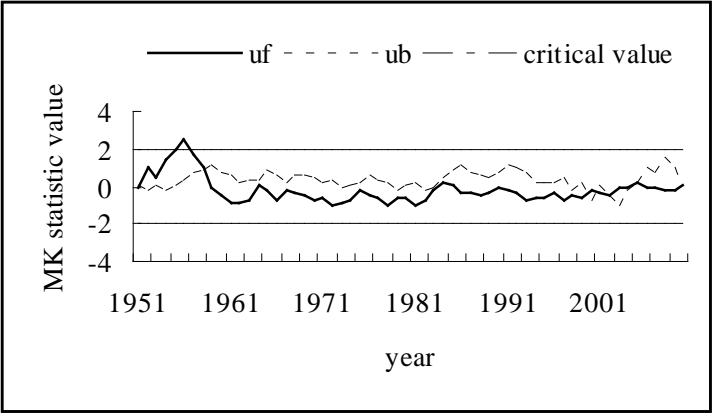

(b)

Figure 3. Saltation analysis for annual precipitation (1951-2010) by the orderly clustering method (a) and M-K sudden change test (b).

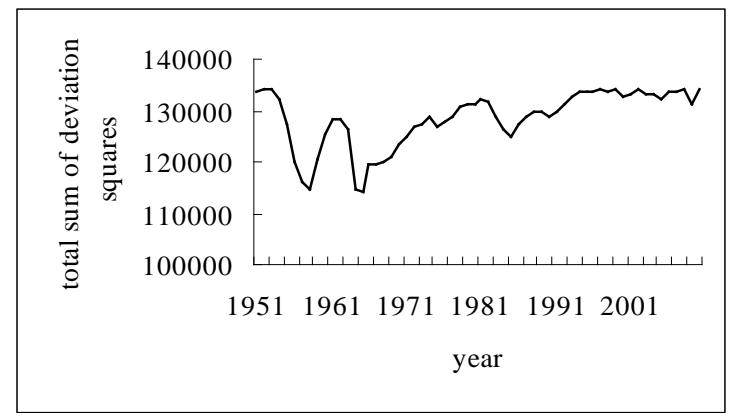

(a)

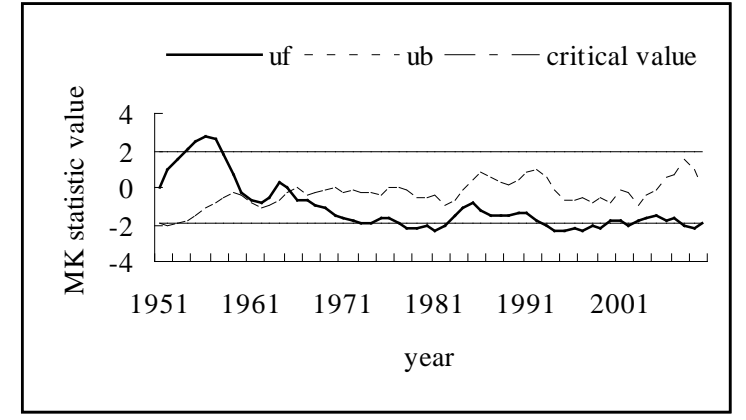

(b)

Figure 4. Saltation analysis for annual stream-flow (1951-2010) by the orderly clustering method (a) and M-K sudden change test (b).

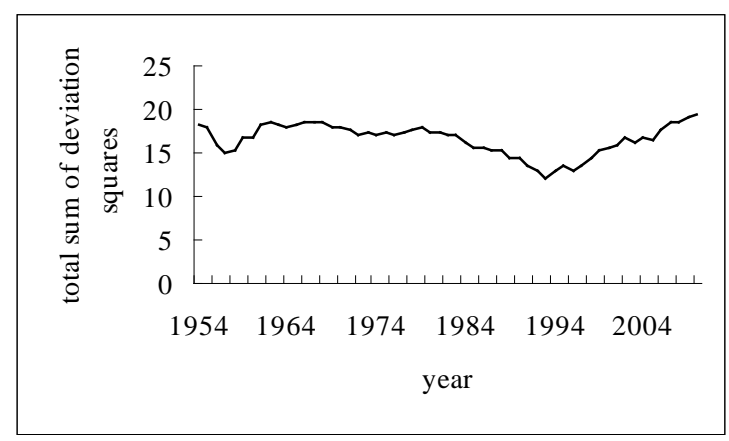

(a)

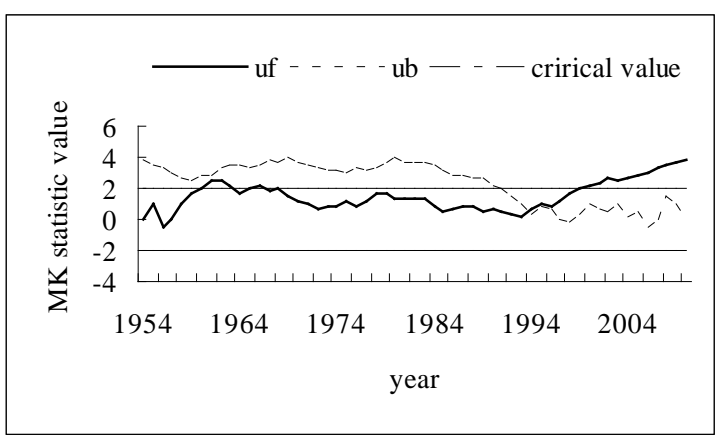

(b)

Figure 5. Saltation analysis for annual temperature (1954-2010) by the orderly clustering method (a) and M-K sudden change test (b).

$=0.923$ and $=0.921$; while for the validation period of $1961-1964, \mathrm{RE}=9.39 \%,=0.915$ and $=0.879$. Compared with the calibration period, the simulation accuracy slightly decreases in the validation period, and this is coincident with the actual situation, due to the continuously increasing of human activities and climate change. While, in the beginning years of human activities, the impact is relatively mall, the simulation accuracy can also reach a high level. Nonetheless, the two pairs of small RE values, high and values in calibration and validation suggest that the calibrated model is applicable and can be used to describe the natural stream-flow in the catchment with fairly high accuracy (Moriasi et al., 2007; Guo et al., 2008). The results insure that the SWAT model with the set of calibrated parameters can be applied to explore the effects of climate change and human activities on the catchment's stream-flow. 
Table 2. The best values of the sensitive parameters in SWAT-CUP.

\begin{tabular}{|c|c|c|c|}
\hline New Rank & Parameter Name & Type of Change & Best Value \\
\hline 1 & CN2.mgt & $\mathrm{R}$ & 0.0528737 \\
\hline 2 & SOL_AWC.sol & $\mathrm{R}$ & 0.324489 \\
\hline 3 & ESCO.hru & V & 0.926328 \\
\hline 4 & SOL_K.sol & $\mathrm{R}$ & 0.0431152 \\
\hline 5 & CH_N2.rte & V & 0.0790498 \\
\hline 6 & ALPHA_BF.gw & V & 0.0506617 \\
\hline 7 & GWQMN.gw & V & 1.37205 \\
\hline 8 & GW_REVAP.gw & V & 0.147555 \\
\hline
\end{tabular}

Note: $\mathrm{R}$ means the original parameter is multiplied by (1+ the given value), $\mathrm{V}$ means the original parameter is replaced by the given value

\subsection{The Effects of Climate Change and Human Activities}

To evaluate the influences of climate change and human activities, the monthly stream-flow at the catchment's outlet (LH station) during the period 1965-2010 are simulated by the calibrated SWAT model. The long-term series is divided from the year 1965 based on the trend and saltation analysis as well as the actual situation (the saltation year of annual stream-flow is 1965, and the three reservoirs in the catchment were started to build in the year 1958 and normally operated nearly in 1960s). The series post-1965 is supposed as the period in which the reservoir regulation has begun to impact the runoff. The measured stream-flow represents the actual situation in which the stream-flow is influenced by both climate change and human activities. The simulated stream-flow represents the original situation in which the stream-flow is influenced only by climate change. Thus, the contrast between the simulated and observed runoff indicates the impact of human activities. Before our study, we compared the land-use in 1980 and 1995, and found that the land-use changes in different types are relatively small, which can be ignored in the following analysis. Therefore, the impact of human activities is simply presumed to be the impact of the water conservancy projects (especially reservoirs).

Figure 7 compares the mean monthly simulated (natural) and measured (actual) stream-flow, the results reveal that monthly actual stream-flow has been increased by about 3.5\% (March) to $109.35 \%$ (December) during December to March and has been reduced by about 12.05\% (November) to 51.05\% (September) during April to November. In order to clearly illustrate the reservoir-induced changes, we summarize the seasonal and annual observed and simulated stream-flow during 1965-2010 (Table 3). In the seasonal scale, the observed streamflow is lower than the observed one in spring, summer and autumn, with the changes is $-35.99 \%,-48.12 \%$ and $-40.61 \%$; in winter, the relative change is $67.04 \%$.

It is obvious that the reservoir regulations have changed the monthly and seasonal recharge regimes (Ye et al., 2003; Lajoie et al., 2007). In the cold season, the extra water is released from reservoirs to relieve the drought condition downstream; as a result, the measured runoff exceeds the simulated one which represents the natural condition without regulation of reservoirs. In the hot season, particularly in summer, the discharge peaks are reduced by the storage of water, and this regulation effectively controls the floods. It is important to emphasize that the reservoir regulations not only impact monthly/seasonal flow regimes, but also affect yearly flow characteristics. As depicted in Table 3, the annual observed stream-flow has reduced by $40.92 \%$, which represent the integrated regulations of reservoirs in different months.

To better understand and quantify the effects of climate change and human activities (regulation of reservoirs), a comparison between observed and simulated stream-flow in the period pre-1965 and post-1965 is necessary. In the natural situation, the change of runoff mainly attributes to the effect of climate change; while in the actual situation, the change is influenced by both climate change and human activities (Dong, 2010; Shi, 2011). The contrast of the measured runoff in the periods of pre-1965 and post-1965 indicates the combined effects of climate change and reservoir regulations. The contrast of the simulated runoff which represents the natural situation in the periods of pre-1965 and post-1965 indicates the effect of climate change. Table 4 depicts the differentiated impacts of climate changes and regulation of reservoirs. 


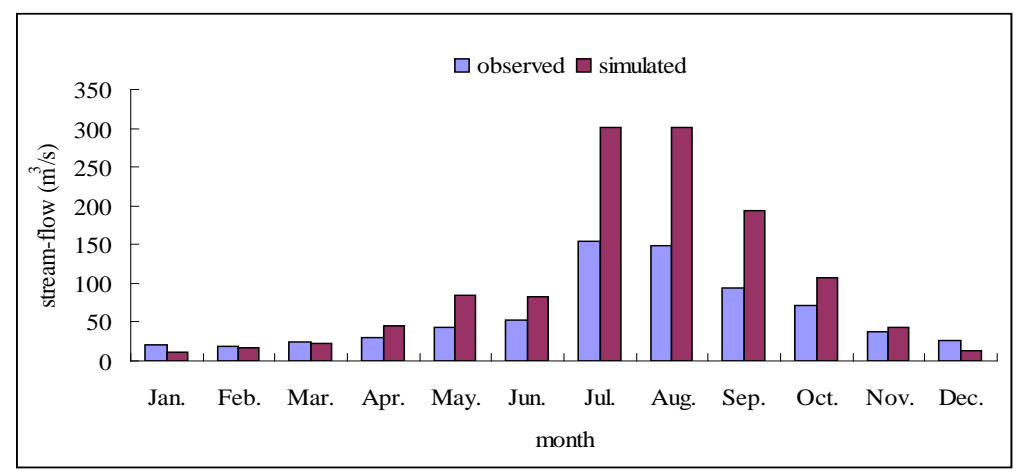

Figure 7. Comparison between mean monthly observed and simulated streamflow at the outlet ( $\mathrm{LH}$ station) of Shaying River catchment during the period $1965-2010$

Table 3. Comparison of the observed and simulated stream-flow in seasonal and annual series.

\begin{tabular}{cccc}
\hline Time & \multicolumn{2}{c}{ Stream-Flow $\left(\mathrm{m}^{3} / \mathrm{s}\right)$} & \multicolumn{2}{c}{$\begin{array}{c}\text { Relative change } \\
\text { ( } \%)\end{array}$} \\
\cline { 2 - 4 } & Observed & Simulated & -35.99 \\
Spring (3 - 5 month) & 32.53 & 50.82 & -48.12 \\
Summer (6 - 8 month) & 119.06 & 229.50 & -40.61 \\
Autumn (9 - 11 month) & 68.26 & 114.93 & 67.04 \\
Winter (12 - 2 month) & 21.57 & 12.91 & -40.92 \\
\hline
\end{tabular}

Table 4. The impacts quantification of the climate changes and human activities.

\begin{tabular}{|c|c|c|c|c|c|c|c|c|c|}
\hline \multirow{2}{*}{ Period } & \multirow{2}{*}{$\mathrm{P}$} & \multirow{2}{*}{$\mathrm{T}$} & \multicolumn{2}{|c|}{ Runoff (mm) } & \multicolumn{3}{|c|}{ Impacts (mm) } & \multirow{2}{*}{$\mathrm{P}_{\mathrm{CC}}(\%)$} & \multirow{2}{*}{$\mathrm{P}_{\mathrm{HC}}(\%)$} \\
\hline & & & Observed & Simulated & $\mathrm{RC}$ & CC & $\mathrm{HC}$ & & \\
\hline $1953-1964$ & 884.7 & 14.3 & 255.84 & 268.31 & & & & & \\
\hline $1965-2010$ & 820.6 & 14.8 & 141.33 & 239.19 & -114.52 & -29.12 & -85.40 & 25.42 & 74.58 \\
\hline
\end{tabular}

Note: $\mathrm{P}$ is precipitation (mm), T is temperature $\left({ }^{\circ} \mathrm{C}\right), \mathrm{RC}$ is total changes, CC is climate changes, $\mathrm{HC}$ is human activities, $\mathrm{P}_{\mathrm{CC}}$ and $\mathrm{P}_{\mathrm{HC}}$ are the impact ratios of climate changes and human activities respectively

From Table 4, following conclusions are obtained: (1) in the period 1965-2010, the annual precipitation decreases and the annual mean temperature increases, leading to a decrease of annual runoff in the catchment; (2) the reducing degree induced by human activities is larger than that induced by climate change, the impact ratios are $74.58 \%$ and $25.42 \%$, respectively, indicating that human activities make a greater contribution on the change of runoff after the constructions of reservoirs.

\section{Conclusions}

The objective of this research is to estimate the stream-flow changes caused by climate variation and human activities. To achieve this purpose, statistical methods are used to analyze the trends and abrupt changes in precipitation, stream-flow and temperature, and then SWAT model is applied to simulate the monthly stream-flow to quantify the effects of natural and artificial factors.

Based on the analyses of trends and abrupt changes, we can conclude that: the trends of precipitation in annual and seasonal scales are all not significant, the annual precipitation shows a slightly upward trend over the past 60 years and the suddenly change occurs in the year 1958; the series of stream-flow indicates decreasing trends in different time series, and most of the trends exceed a confidence level, for the annual stream-flow, a 
saltation point is detected in the year 1965; the temperature series show significant increasing trends except for the summer series which represents a downward trend, and a abrupt change happens in 1993. These different changes reveal that the human activities are crucial in influencing hydrological processes.

The SWAT model is proved to be applicable in the catchment with fairly high accuracy both in the calibration and validation periods. This insures that the calibrated model can be used to assess the flow changes induced by climate and human activities, particularly reservoirs. The results show that the regulation of reservoirs in different months and seasons has evidently altered the discharge regimes, the stream-flow increases in the cold season and decreases in the hot season (especially in summer). The quantification of the impacts of climate change and human activities suggests that both of the two factors result in a decreasing in stream-flow, but the human activities (reservoir regulations) play a more pronounced role in this catchment.

This study clearly points out the importance of human activities in the flow changes, but the process of the analysis includes many hypotheses, and we ignore the effects of the land-use changes in the catchment. More efforts are needed to explore the influences of different human activities for effective planning, management and sustainable development of water projects in the future.

\section{Acknowledgements}

The first author thanks the following financial support: Major Program of National Natural Science Foundation of China (51190091) and the National Natural Science Foundation of China

(41371048/41001011/40901015/D0101012/51079038).

\section{References}

Arnold, J. G., Srinivasan, R., Muttiah, R. S., \& Williams, J. R. (1998). Large Area Hydrologic Modeling and Assessment Part I: Model Development. Journal of the American Water Resources Association, 34, 73-89. http://dx.doi.org/10.1111/j.1752-1688.1998.tb05961.x

Beven, K., \& Binley, A. (1992). The Future of Distributed Models: Model Calibration and Uncertainty Prediction. Hydrological Processes, 6, 279-298. http://dx.doi.org/10.1002/hyp.3360060305

Cao, M., Zhang, C., \& Zhou, H. (2008). Change Trend of Rainfall and Runoff in Upstream of Fengman Basin under Influence of Human Activities. Journal of China Hydrology, 28, 86-89. (In Chinese)

Chaouche, K., Neppel, L., Dieulin, C., Pujol, N., Ladouche, B., Martin, E., Salas, D., \& Caballero, Y. (2010). Analysis of Precipitation, Temperature and Evapotranspiration in a French Mediterranean Region in the Context of Climate Change. Comptes Rendus Geoscience, 342, 234-243. http://dx.doi.org/10.1016/j.crte.2010.02.001

Ding, J., \& Deng, Y. (1988). Stochastic Hydrology. Chengdu: Chengdu University of Science and Technology Press. (In Chinese)

Dong, W. (2010). Study on the Effect of Human Activities and Climate Change on Hydrology and Water Resources-A Case Study in Jinghe Basin, Xinjiang. Jinghe University. (In Chinese)

Editorial (2008). Assessing Impacts, Adaptation and Vulnerability: Reflections on the Working Group II Report of the Intergovernmental Panel on Climate Change. Global Environmental Change, 18, 4-7.

Gebremicael, T. G., Mohamed, Y. A., Betrie, G. D., Zaag, P., \& Teferi, E. (2013). Trend Analysis of Runoff and Sediment Fluxes in the Upper Blue Nile Basin: A Combined Analysis of Statistical Tests, Physically-Based Models and Landuse Maps. Journal of Hydrology, 482, 57-68. http://dx.doi.org/10.1016/j.jhydrol.2012.12.023

Guo, H., Hu, Q., \& Jiang, T. (2008). Annual and Seasonal Streamflow Responses to Climate and Land-Cover Changes in the Poyang Lake Basin, China. Journal of Hydrology, 355, 106-122. http://dx.doi.org/10.1016/j.jhydrol.2008.03.020

Guo, S., Wang, J., Xiong, L., Ying, A., \& Li, D. (2002). A Macro-Scale and Semi-Distributed Monthly Water Balance Model to Predict Climate Change Impacts in China. Journal of Hydrology, 268, 1-15. http://dx.doi.org/10.1016/S0022-1694(02)00075-6

Hofmann, M. E., Hinkel, J., \& Wrobel, M. (2011). Classifying Knowledge on Climate Change Impacts, Adaptation, and Vulnerability in Europe for Informing Adaptation Research and Decision-Making: A Conceptual Meta-Analysis. Global Environmental Change, 21, 1106-1116. http://dx.doi.org/10.1016/j.gloenvcha.2011.03.011

IPCC (1995). IPCC Second Report of Assessment of Climate Change. London: Cambridge University Press.

Isik, S., Dogan, E., Kalin, L., Sasal, M., \& Agiralioglu, N. (2008). Effects of Anthropogenic Activities on the Lower Sakarya River. Catena, 75, 172-181. http://dx.doi.org/10.1016/j.catena.2008.06.001

Kendall, M. G. (1975). Rank Correlation Methods. London: Griffin. 
Kottegoda, N., Natale, L., \& Raiteri, E. (2011). Simulation of Climatic Series with Nonstationary Trends and Periodicities. Journal of Hydrology, 398, 33-43. http://dx.doi.org/10.1016/j.jhydrol.2010.12.003

Lajoie, F., Assani, A. A., Roy, A. G., \& Mesfioui, M. (2007). Impacts of Dams on Monthly Flow Characteristics: The Influence of Watershed Size and Seasons. Journal of Hydrology, 334, 423-439. http://dx.doi.org/10.1016/j.jhydrol.2006.10.019

Legates, D. R., \& McCabe, G. J. (1999). Evaluating the Use of “Goodness-of-Fit” Measures in Hydrologic and Hydroclimatic Model Validation. Water Resources Research, 35, 233-241. http://dx.doi.org/10.1029/1998WR900018

Liu, Q., Yang, Z., \& Cui, B. (2008). Spatial and Temporal Variability of Annual Precipitation during 1961-2006 in Yellow River Basin, China. Journal of Hydrology, 361, 330-338. http://dx.doi.org/10.1016/j.jhydrol.2008.08.002

Magilligan, F. J., \& Nislowb, K. H. (2005). Changes in Hydrologic Regime by Dams. Geomorphology, 71, 61-78. http://dx.doi.org/10.1016/j.geomorph.2004.08.017

Mimikou, M., Kouvopoulos, Y., Cavadias, G., \& Vayianos, N. (1991). Regional Hydrological Effects of Climate Changes. Journal of Hydrology, 123, 119-146. http://dx.doi.org/10.1016/0022-1694(91)90073-Q

Mithell, J. M., Dzerdzeevskii, B., Flohn, H., Hofmeyr, W. L., Lamb, H. H., Rao, K. N., \& Wallén, C. C. (1966). Climatic Change. Report of a Working Group of the Commission for Climatology, WMO Technical Note No. 79, World Meteorological Organization, p. 79.

Moriasi, D., Arnold, J., Van Liew, M., Bingner, R., Harmel, R., \& Veith, T. (2007). Model Evaluation Guidelines for Systematic Quantification of Accuracy in Watershed Simulations. Transactions of the ASABE, 50, 885-900. http://dx.doi.org/10.13031/2013.23153

Morris, M. D. (1991). Factorial Sampling Plans for Preliminary Computational Experiments. Technometrics, 33, $161-174$. http://dx.doi.org/10.1080/00401706.1991.10484804

Neitsch, S. L., Arnold, J. G., Kiniry, J. R., \& Williams J. R. (2005a). SWAT Theoretical Documentation Version (2005). Temple, TX: Grassland, Soil and Water Research Laboratory, Agricultural Research Service.

Neitsch, S. L., Arnold, J. G., Kiniry, J. R., \& Williams, J. R. (2005b). SWAT Input/Output File Documentation Version (2005). Temple, TX: Grassland, Soil and Water Research Laboratory, Agricultural Research Service.

Panagoulia, D., \& Dimou, G. (1997). Linking Space-Time Scale in Hydrological Modeling with Respect to Global Climate Change: Model Properties and Experimental Design. Journal of Hydrology, 194, 15-37. http://dx.doi.org/10.1016/S0022-1694(96)03220-9

Parry, M. L., Canziani, O. F., Palutikof, J. P., van der Linden, P. J., \& Hanson, C. E., IPCC (2007). Climate Change 2007: Impacts, Adaptation and Vulnerability. Contribution of Working Group II to the Fourth Assessment Report of the Intergovernmental Panel on Climate Change, Cambridge: Cambridge University Press, 976p.

Rinaldi, M. (2003). Recent Channel Adjustments in Alluvial Rivers of Tuscany, Central Italy. Earth Surface Process and Landforms, 28, 587-608. http://dx.doi.org/10.1002/esp.464

Romanowicz, R., Beven, K., \& Tawn, J. (1994). Evaluation of Predictive Uncertainty in Nonlinear Hydrological Models Using a Bayesian Approach. Statistics for the Environment, 2, 297-317.

Saltelli, A., Chan, K., \& Scott, E. M. (2000). Sensitivity Analysis. New York: Wiley.

Santhi, C., Arnold, J. G., Williams, J. R., Dugas, W.A., Srinivasan, R., \& Hauck, L. M. (2001). Validation of the SWAT Model on a Large River Basin with Point and Nonpoint Sources. Journal of the American Water Resources Association, 37, 1169-1188. http://dx.doi.org/10.1111/j.1752-1688.2001.tb03630.x

Saxton, K. E., \& Willey, P. H. (2005). Soil Water Characteristics Hydraulic Properties Calculator. Agricultural Research Service.

Shi, P., M, X., Chen, X., Qu, S., \& Zhang, Z. (2013a). Analysis of Variation trends in Precipitation in an Upstream Catchment of Huai River. Mathematical Problems in Engineering, 2013, Article ID: 929383. http://dx.doi.org/10.1155/2013/929383

Shi, P., Ma, X., Hou, Y., Li, Q., Zhang, Z., Qu, S., Chen, C., Cai, T., \& Fang, X. (2013b). Effects of Land-Use and Climate Change on Hydrological Processes in the Upstream of Huai River, China. Water Resource Manage, 27, 1263-1278. http://dx.doi.org/10.1007/s11269-012-0237-4

Shi, Y. (2011). The influence of Climate Change and Human Activities on Basin Water Resources and Cases Study. Dalian: Dalian University of Technology. (In Chinese)

Wang, X. (2000). Characteristics Analysis of Rainfall in the Upper Reaches of the Shaying River Basin. Hydrology, 20, 5355. (In Chinese)

Wu, K., \& Johnston, C. A. (2007). Hydrologic Response to Climatic Variability in a Great Lakes Watershed: A Case Study with the SWAT Model. Journal of Hydrology, 337, 187-199. http://dx.doi.org/10.1016/j.jhydrol.2007.01.030

Xu, C. Y., \& Singh, V. P. (1998). A Review on Monthly Water Balance Models for Water Resources Investigations. Water Resources Management, 12, 31-50. http://dx.doi.org/10.1023/A:1007916816469 
Ye, B., Yang, D., Kane, D.L., 2003. Changes in Lena River Streamflow Hydrology: Human Impacts versus Natural Variations. Water Resources Research, 39, 1200 8-1:8-14.

Zhang, X., Srinivasan, R., \& Hao, E. (2007). Predicting Hydrologic Response to Climate Change in the Luohe River Basin Using the SWAT Model. Transactions of the ASABE, 50, 901-910. http://dx.doi.org/10.13031/2013.23154

Zhang, Y., Xia, J., Liang, T., \& Shao, Q. (2010). Impact of Water Projects on River Flow Regimes and Water Quality in Huai River Basin. Water Resources Management, 24, 889-908. http://dx.doi.org/10.1007/s11269-009-9477-3 